\title{
CRITICAL THINKING SKILLS AMONG MOROCCAN PHD STUDENTS OF HEALTH SCIENCES
}

\author{
Imane Ghazlane $^{1,2}$, Bouzekri Touri ${ }^{1}$, Mohamed Bergadi ${ }^{1}, \&$ Khalid Marnoufi ${ }^{1}$ \\ ${ }^{1}$ Multidisciplinary Laboratory of Information, Communication and Education Sciences and Technology \\ (LAPSTICE), Ben M'sik Faculty of Science, Hassan II University, post box 7955, Casablanca (Morocco) \\ ${ }^{2}$ Higher Institute of Nursing and Health Technology Professions Casablanca-Settat, Morocco Street \\ Faidouzi Mohamed, 20250 Casablanca (Morocco)
}

\begin{abstract}
The significant weakness in problem solving and innovation continues to affect scientific production in Morocco. To this end, many strategies and reforms have been put in place to address the various problems raised.

In this perspective, the national strategy for the development of scientific research by 2025 indicates, among other things, the proper conduct and methodological integrity of research work.

The theory states that critical thinking is the intellectual basis of the scientific research method, furthermore it was been empirically demonstrated that students with strong critical thinking skills perform well in research methodology. Therefore, the close relationship between critical thinking skills and performance in research methodology application, stipulates highlighting the potential of young researchers in this area. The present work is the subject of an exploratory study that opts to reveal the critical thinking skills, considered an essential foundation for any research methodology, in 25 apprentice researchers in the health sciences.

The salient findings of the study were, a moderate overall score of critical thinking skills, and a significant correlation between the overall score of the set of skills and the scores of their Master's monographs, furthermore, In addition, the correlation indicates that the success of their dissertation work was related to the deduction, evaluation and inference subscales of the HSRT.
\end{abstract}

Keywords: Scientific research, critical thinking skills, health science, HSRT.

\section{Introduction}

Scientific research involves thinking and critical thinking to confront the various challenges of acquiring knowledge, understanding reality and promoting quality of life in a constantly changing world.

Ennis (1985), mentions that critical thinking is "asking and answering questions, defining terms and identifying hypotheses", Facione (1990) stated that critical thinking is "interpreting and explaining" on the other hand Halpern (1998), Paul (1992), Willingham (2007), added that critical thinking consists of "making conclusions using inductive or deductive reasoning".

Moreover, Case (2005) showed that critical thinking embodies judgment and evaluation, and decision making or problem solving; while Benítez and Canales (2013) have also added that critical thinking is considered a resilience factor that chooses to increase the capacity of people to identify, challenge, solve problems and become stronger to face new challenges.

Moreover, critical thinking is one of the most important skills that a researcher must possess in order to reach an optimal solution (Indrawatiningsih, N, Purwanto, As'ari, A. R., Dwiyana, Sudirman, \& Rahardi, R, 2019).

The critical thinking has been defined as skills (Facione, 1990) (Halpern, 1998), which include analysis, inference, evaluation, inference, and induction.

Harvey W. Wallmann, Donald l. Hoover (2012) indicate that advanced critical thinking skills are necessary for students preparing for and/or enrolled in professional programs. In particular, in health science, critical thinking skills are increasingly needed in academic and clinical settings to ensure evidence-based practice, (Harvey W. Wallmann, Donald 1. Hoover, and 2012) (Meherali, 2016).

In addition, critical thinking skills ensure a quality approach that fosters a certain methodological integrity, which ultimately provides useful results for research users. (Roller and Lavrakas, 2015). 
The present study is descriptive and exploratory, it consists of a diagnosis of critical thinking skills among doctoral students in health sciences, highlighting their abilities to apply and interpret their research methods, and identifying which skills are in use and which need to be developed in order to promote their research process.

\section{Method}

2-1 / Participants: There are $25 \mathrm{PhD}$ students in health sciences, selected using a simple random sampling technique, the study setting is Casablanca Faculty of Medicine, $79 \%$ of the participants were female, $82 \%$ are aged between 24 and 30 years old,

2-2: Instrument and procedure: After receiving permission from the committee, a pre-test has administered to 09 students to see its adaptability and validity in our target population,

Students took the Health Sciences Reasoning Test (HSRT), It is considered the most reliable and widely used instrument for measuring critical thinking skills in the health sciences (Insight assessment, 2019). The test provided a holistic measure of critical thinking (overall score) and individual scores for the range of cognitive skills identified as critical skills in the critical thinking process, such as induction, deduction, analysis, inference and evaluation. The test is specific for health context, and it consists of 33 multiple-choice questions on a California Insight assessment platform, the time required to complete the test is 50 minutes.

\section{Results}

The overall score of (HSRT) among the participants is just moderate, and the percentile for this group is 35, based on the distribution of overall score percentile for the participants in this group, as compared to an aggregate sample of four-year HSRT students.

In addition, there is a significant correlation between the overall score and the average score obtained from the participants' research work, which is (0.73). And this correlation is related on deduction, inference, and evaluation.

However, there is no correlation between the skills related to analysis and induction and their thesis rating.

The present study reveals a moderate score on the set of critical thinking skills among the study participants, and a significant correlation between the overall score and their thesis rating, furthermore, the skills of induction and analysis require rigorous development.

\section{Discussion}

The overall score is just moderate, with a significant correlation between the overall score and participants' final dissertation scores, these results are corroborate to those of a meta-analysis of studies evaluating critical thinking test scores and academic achievement of health profession students (Reale MC, Riche DM, Witt BA, Baker WL, Peeters MJ, 2018; Touri B. \& al., (2016).

However, the results on analysis and induction skills show that there is underperformance in this area, moreover; this is similar with numerous studies and reports witch state that graduates students have not the critical thinking and problem-solving skills in the classroom and in their jobs (Nold, 2017).

Because, conclusions, assumptions, recommendations, or decisions based on inaccurate analysis can bias the study, even if they have been using excellent inference skills.

In addition, Harvey W. Wallmann and Donald. Hoover, (2012) indicate that those students who have given up on continuing their work in the health sciences are the ones who do not have the critical thinking skills necessary for success, moreover, the graduates student with less critical thinking skills have higher unemployment rates,(Kelsch,M and Friesner,D ,2014)

By the way, the students must be trained by the professor who have been trained in the concepts of critical thinking and the methods necessary to develop critical thinking skills (Nold, 2017)

Furthermore, Willingham (2019) announces that in order to strengthen critical thinking skills among students, a continuous practice of critical thinking remains essential.

In the Moroccan context, and in order to improve scientific production, it is essential to focus on academic circles and strengthen their analytical skills and to implement a teaching-learning approach based on critical thinking to enable students to be independent, capable of making in-depth decisions, building new knowledge and dealing with professional and societal problems. 


\section{Conclusion}

This study reveals a moderate overall score of the set of critical thinking skills among an elite group of health science students, and there is a significant correlation between the final projects rating and the overall score of the different skills. Moreover, there is a deficit in analysis and induction skills requires some intervention to build capacity in this area.

Furthermore, the apprentice researchers must perform well on the set of critical thinking skills and especially the evaluative and analytical skills that ensure useful results in health sciences research.

Thus, it will be useful to integrate the critical thinking approach into the training curriculum, particularly in university studies, so it remains essential to merge critical thinking into the various education programs from an early age, for more practice. Because, Smart method will definitely lead to smart results that will serve societies in general.

In addition, an evaluation of research methods for graduation work in the health sciences will be the subject of a future study.

\section{References}

Benítez and Canales (2013). Critical Thinking as a Resilience Factor in an Engineering Program Creative (http://www.scirp.org/journal/ce) http://dx.doi.org/10.4236/ce.2013.49087

Boisvert, J. (2015). Critical thinking: definition, illustration and applications. http://www.cdc.qc.ca/pdf/033878.

Collins, Kathleen M.; Onwuegbuzie, Anthony J. (2000). Relationship between Critical Thinking and Performance in Research Methodology Courses. ERIC Number: ED448199

Ennis, R. H. (1989). Critical Thinking and Subject Specificity: Clarification and Needed Research. Educational Researcher, 18(3), 4-10. https://doi.org/10.3102/0013189X018003004

Ennis, R. H. (1993). Critical thinking assessment. Theory into Practice, 32(3), 179-186. https://doi.org/10.1080/00405849309543594

Facione, P. (1989). Critical Thinking: A Statement of Expert Consensus for Purposes of Educational Assessment and Instruction. https://www.researchgate.net/publication/242279575

Fortin, F.M. (2010). Fondements et étapes du processus de recherche. Chenelière education.

Halpern, D. F. (1998). Teaching critical thinking for transfer across domains: Disposition, skills, structure training, and metacognitive monitoring. American Psychologist, 53(4), 449-455. https://doi.org/10.1037/0003-066X.53.4.449

Kelsch, M. P., \& Friesner, D. L. (2014). The health sciences reasoning test in the pharmacy admissions process. American Journal of Pharmaceutical Education, 78(1), 9. https://doi.org/10.5688/ajpe7819

Meherali, S.M. Research Utilization and Critical Thinking of Undergraduate Nursing Students. Retrieved from https:/era.library.ualberta.ca/items/e2306501-bf3b-4ccb-9d07fdd8520695dd/view/65e24cc7-5b43-4c3b-b916-797650ea255c/Meherali_Salima_M_201607

Nold, H. (2017). Using Critical Thinking Teaching Methods to Increase Student Success: An Action Research Project. https://files.eric.ed.gov/fulltext/EJ1136016.pdf

Reale, M. C., Riche, D. M., Witt, B. A., Baker, W. L., \& Peeters, M. J. (2018). Development of critical thinking in health professions education: A meta-analysis of longitudinal studies. Currents in Pharmacy Teaching \& Learning, 10(7), 826-833. https://doi.org/10.1016/j.cptl.2018.04.019

Roller and Lavrakas. (2015). Critical Thinking in Qualitative Research Design. (pp. 20-21).

Stratégie Nationale Pour Le Développement De La Recherche Scientifique a L'horizon 2025.

Wallmann, H. W., \& Hoover, D. L. (2012). Research and Critical Thinking: An Important Link for Exercise Science Students Transitioning to Physical Therapy. https://www.ncbi.nlm.nih.gov/pmc/articles/PMC4738974/

Willingham, D. T. (2007). Critical thinking: Why is it so hard to teach? https://eric.ed.gov/?id=EJ794281

Willingham, D.T. (2019) How to Teach Critical Thinking. https://education.nsw.gov.au/content/dam/maineducation/teaching-and-learning/education-for-a-changing-world/media/documents/How-to-teachcritical-thinking-Willingham.pdf 